Prepared for the U.S. Department of Energy

Under Contract DE-AC05-76RL01830

\title{
Follow-on to a report on the Applicability of the "Gallet Equation" to the Vegetation Clearances of NERC Reliability Standard FAC-003-2
}

H Kirkham

August 2012

Pacific Northwest

NATIONAL LABORATORY

Proudly Operated by Battelle Since 1965 



\title{
DISCLAIMER
}

This documentation was prepared as an account of work sponsored by an agency of the United States Government. Neither the United States Government nor any agency thereof, nor Battelle Memorial Institute, nor any of their employees, makes any warranty, express or implied, or assumes any legal liability or responsibility for the accuracy, completeness, or usefulness of any information, apparatus, product, or process disclosed, or represents that its use would not infringe privately owned rights. Reference herein to any specific commercial product, process, or service by trade name, trademark, manufacturer, or otherwise does not necessarily constitute or imply its endorsement, recommendation, or favoring by the United States Government or any agency thereof, or Battelle Memorial Institute. The views and opinions of authors expressed herein do not necessarily state or reflect those of the United States Government or any agency thereof.

\author{
PACIFIC NORTHWEST NATIONAL LABORATORY \\ operated by \\ BATTELLE \\ for the \\ UNITED STATES DEPARTMENT OF ENERGY \\ under Contract DE-AC05-76RL01830
}

Printed in the United States of America
Available to DOE and DOE contractors from the Office of Scientific and Technical Information, P.O. Box 62, Oak Ridge, TN 37831-0062; ph: (865) 576-8401, fax: (865) 576-5728 email: reports@adonis.osti.gov

Available to the public from the National Technical Information Service, U.S. Department of Commerce, 5285 Port Royal Rd., Springfield, VA 22161

ph: (800) 553-6847, fax: (703) 605-6900

email: orders@ntis.fedworld.gov

online ordering: http://www.ntis.gov/ordering.htm

(3) This document was printed on recycled paper. 

PNNL-21220-1

\section{Follow-on to a report on the Applicability of the "Gallet Equation" to the Vegetation Clearances of NERC Reliability Standard FAC-003-2}

H Kirkham

August 2012

Prepared for U.S. Department of Energy under Contract DE-AC05-76RL01830

Pacific Northwest National Laboratory Richland, Washington 99352 


\title{
Follow-on to a report on the Applicability of the "Gallet equation" to the vegetation clearances of NERC Reliability Standard FAC-003-2
}

\author{
Harold Kirkham, PNNL
}

\section{Executive Summary}

In earlier work, a study for FERC's Office of Electrical Reliability done at the Pacific Northwest National Laboratory examined a NERC proposed standard specifying clearances between vegetation and power lines. The method proposed for calculating the clearances was based on the results of testing for high-voltage line designs. An equation developed to relate the results of testing with rod-plane gaps to proposed tower window sizes was incorporated into the calculations. ${ }^{1}$

The equation in question, sometimes called the "Gallet equation," describes the insulation performance of the atmosphere for air gaps of a few meters. The equation was described in the PNNL study as a good and simple-to-use way to solve a problem made difficult by the nonlinear interactions of the variables.

For calculations based on this equation, a certain set of assumptions must be made. In particular, a value for a quantity called the "gap factor" is needed. This is the amount by which the gap to be modeled by the equation is stronger than the reference gap that was used in developing the Gallet equation. That reference gap is the gap between a rod and a plane.

This new report was also commissioned by FERC's Office of Electrical Reliability. The scope of the study was to examine the effect on flashover probabilities of assuming an incorrect value for the gap factor. In particular, the flashover probability is found that would result from using a value of 1.3 when a gap factor of 1.0 should be applied in the Gallet equation.

It is shown in this follow-on report that with these assumptions the probability of a flashover changes from being extremely unlikely (about 1 in 1000 chance) to a virtual certainty (about 97\% chance).

\footnotetext{
${ }^{1}$ G. Gallet, G. Leroy, R. Lacey, I. Kromer, General Expression for Positive Switching Impulse Strength Valid Up to Extra Long Air Gaps, IEEE Trans. Power Apparatus and Systems, Vol. PAS-94, No. 6, Nov./Dec. pp. 19891993, 1975.
} 


\section{Table of Contents}

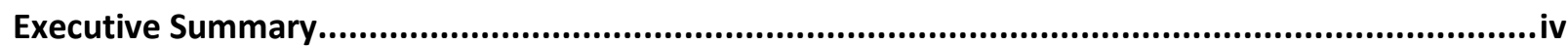

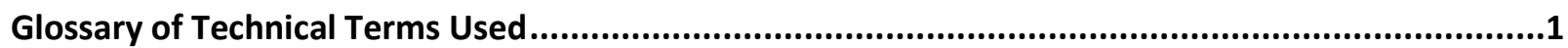

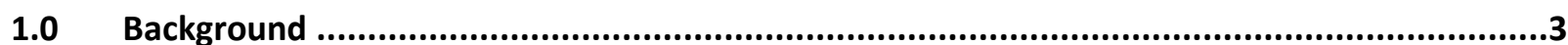

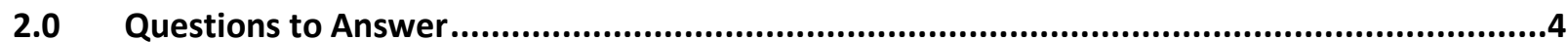

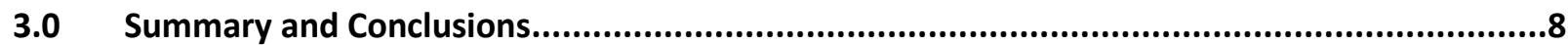




\section{List of Figures}

Figure 1 Solution of Gallet equation with two different gap factors .......................................... 4

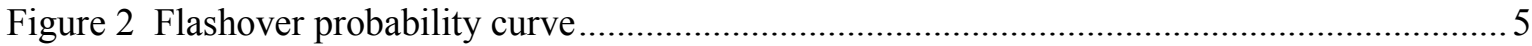

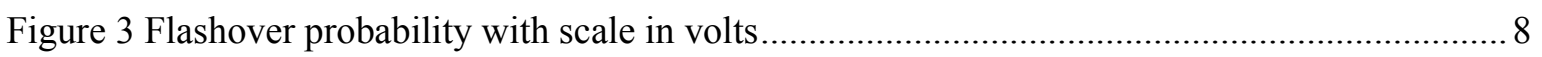




\section{Glossary of Technical Terms Used}

The field of high voltage engineering advances by communicating the results of its research. To be effective, the communication requires the use of language specific to the topic: the jargon of the technology.

The glossary below has been provided by the author with the intent of being a handy reference for the reader who is not familiar with the language of high voltage engineering. It is not a complete dictionary, but has been written to include only the jargon words that will be encountered in this report.

The glossary has been presented in a "logical" sequence rather than alphabetical. The entries are explained or commented on as seems appropriate to the author. (See, for example, the terms "flashover" and "sparkover.")

\begin{tabular}{|c|c|}
\hline $\begin{array}{l}\text { EHV } \\
\text { Extra High Voltage }\end{array}$ & $\begin{array}{l}\text { The term used for power lines operating in the range of } 345 \text { to } 765 \mathrm{kV} \text { phase to } \\
\text { phase. Such lines have been in operation since the } 1960 \mathrm{~s} \text {. }\end{array}$ \\
\hline $\begin{array}{l}\text { UHV } \\
\text { Ultra High Voltage }\end{array}$ & $\begin{array}{l}\text { The term used for power lines operating above EHV levels. No lines of this } \\
\text { class are operational, though test facilities have been constructed in several } \\
\text { countries. }\end{array}$ \\
\hline insulation system & $\begin{array}{l}\text { An arrangement of insulation that serves to keep conductors at different } \\
\text { potentials apart, thereby preventing current flow. Such systems may involve } \\
\text { glass or ceramic materials, or organics such as paper, oil and various plastics, as } \\
\text { well as air or vacuum. }\end{array}$ \\
\hline impulse testing & $\begin{array}{l}\text { The testing of insulation systems by means of laboratory-generated impulses at } \\
\text { high voltage. The tests may be indoor or outdoor. For line-design purposes, } \\
\text { outdoor testing is considered more realistic and therefore preferred. }\end{array}$ \\
\hline rod-plane gap & $\begin{array}{l}\text { In testing high voltage insulation, a convenient configuration that produces } \\
\text { repeatable results is the rod to plane gap. The rod in question is circular in } \\
\text { section, and may have any orientation: the plane is orthogonal to it. The end of } \\
\text { the rod is customarily terminated by making it hemispherical. }\end{array}$ \\
\hline flashover & $\begin{array}{l}\text { The end of a process by which an insulation system fails and an electric current } \\
\text { flows. According to IEEE Std 4, the term should be reserved for the failure of } \\
\text { solid insulation, but it is in general use in the US applied to air breakdown as } \\
\text { well. }\end{array}$ \\
\hline sparkover & $\begin{array}{l}\text { The term that IEEE Std } 4 \text { reserves for the breakdown of gas insulation. The } \\
\text { term is used by European researchers in preference to flashover. }\end{array}$ \\
\hline withstand & $\begin{array}{l}\text { The capability of an insulation system to function as an insulator when a high } \\
\text { voltage is applied. }\end{array}$ \\
\hline $\begin{array}{l}\text { Gaussian (or } \\
\text { Normal) } \\
\text { distribution }\end{array}$ & $\begin{array}{l}\text { A probability distribution that has a characteristic bell-shaped curve. The center } \\
\text { of the distribution is the average value. The width of the curve gives an } \\
\text { indication of the spread of the things being represented. The distribution is } \\
\text { representative of many natural phenomena, and is mathematically well- } \\
\text { characterized. }\end{array}$ \\
\hline $\begin{array}{l}\text { overvoltage, } \\
\text { transient }\end{array}$ & $\begin{array}{l}\text { A short-term condition in which the voltage on a line exceeds its usual value. } \\
\text { The overvoltage may be due to a lightning strike (which can deposit charge } \\
\text { directly onto a conductor) or to switching (which can increase the voltage by }\end{array}$ \\
\hline
\end{tabular}




\begin{tabular}{|l|l|}
\hline overvoltage & $\begin{array}{l}\text { means of charge trapped on a line). Lighting is fast compared to switching } \\
\text { surges. On EHV and UHV lines, switching surges are larger in amplitude. }\end{array}$ \\
\hline risetime & $\begin{array}{l}\text { Broadly, the time taken for a pulse to reach its maximum value. Since pulses (or } \\
\text { surges) usually have the characteristic that they start gradually, and reach their } \\
\text { maximum value gradually, engineers usually define the risetime as the time } \\
\text { between 10\% and 90\% of the peak value. In high voltage testing, the time } \\
\text { between 30\% and 90 is more commonly used. }\end{array}$ \\
\hline critical flashover & $\begin{array}{l}\text { The voltage at which a surge is 50\% likely to cause a flashover. The word } \\
\text { critical means that the risetime of the surge is at the value known to result in the } \\
\text { lowest flashover voltage. In testing insulation systems with surges, the flashover } \\
\text { may occur before the peak value is reached, or (rarely) after the peak has been } \\
\text { passed. It customary to specify the voltage of the peak, nevertheless, rather than } \\
\text { the actual value at the instant of the flashover. }\end{array}$ \\
\hline tower window & $\begin{array}{l}\text { The space created by the structure of a tower, and through which the line } \\
\text { conductor passes. The window may be square in section, or may have more } \\
\text { sides. In an EHV or UHV line the conductor usually passes through the window } \\
\text { just below the center, and the insulators that support the conductor are given a } \\
\text { slightly longer gap than the air underneath. }\end{array}$ \\
\hline gap factor & $\begin{array}{l}\text { The ratio of the CFO of a test object to the CFO of a rod-plane gap for the same } \\
\text { spacing. For any given spacing, a rod-plane gap gives consistently the lowest } \\
\text { CFO voltage. Just how much stronger the gap of a tower window is can be } \\
\text { determined experimentally. Once the factor has been found for a certain shape } \\
\text { of window, it can be applied to other gap spacings of the same shape to } \\
\text { determine a corrected or adjusted CFO. }\end{array}$ \\
\hline
\end{tabular}




\section{Follow-on to a report on the Applicability of the "Gallet equation" to the vegetation clearances of NERC Reliability Standard FAC-003-2}

\subsection{Background}

In earlier work, a study for FERC's Office of Electrical Reliability done at the Pacific Northwest National Laboratory examined a NERC proposed standard specifying clearances between vegetation and power lines. The method proposed for calculating the clearances was based on the results of testing for high-voltage line designs. An equation that had been developed to relate the results of testing with rod-plane gaps to proposed tower window sizes was incorporated into the NERC calculations. ${ }^{1}$

The equation in question, sometimes called the "Gallet equation," describes the insulation performance of the atmosphere for air gaps of a few meters. The equation was described in the PNNL study as a good and simple-to-use way to solve a problem made difficult by the nonlinear interactions of the variables.

This new report was also commissioned by FERC's Office of Electrical Reliability. The scope of the study was to examine the effect on flashover probabilities of assuming an incorrect value for a quantity called the gap factor. In particular, the flashover probability is examined that would result from using a value of 1.3 when a gap factor of 1.0 should be applied in the Gallet equation.

The gap factor is the amount by which the gap to be modeled by the equation is stronger than the reference gap that was used in developing the Gallet equation. That reference gap is the gap between a rod and a plane.

The equation described by Gallet in his 1975 paper was a computer-based curve fit to a large quantity of experimental data. The experiments used a rod (usually vertical) and a plane (usually the ground) because the results were consistent, and could be adapted to other electrode geometries. The field of interest was the design of transmission line towers. The equation Gallet gave was

$$
U=k \cdot \frac{3.4}{1+\frac{8}{d}}
$$

\footnotetext{
${ }^{1}$ G. Gallet, G. Leroy, R. Lacey, I. Kromer, General Expression for Positive Switching Impulse Strength Valid Up to Extra Long Air Gaps, IEEE Trans. Power Apparatus and Systems, Vol. PAS-94, No. 6, Nov./Dec. pp. 1989$1993,1975$.
} 
Where $U$ is the critical sparkover voltage in $\mathrm{MV}$, and $d$ is the gap in meters. The constant $k$ is called the gap factor.

Once the gap factor was established (experimentally) for a given tower window geometry, the equation could be used to find the relation between voltage and gap over quite a wide range. Figure 1 shows the solution of the equation with two different gap factors. The effect of the factor is clearly to re-scale the vertical axis. The voltage values simply change in proportion to the gap factor.

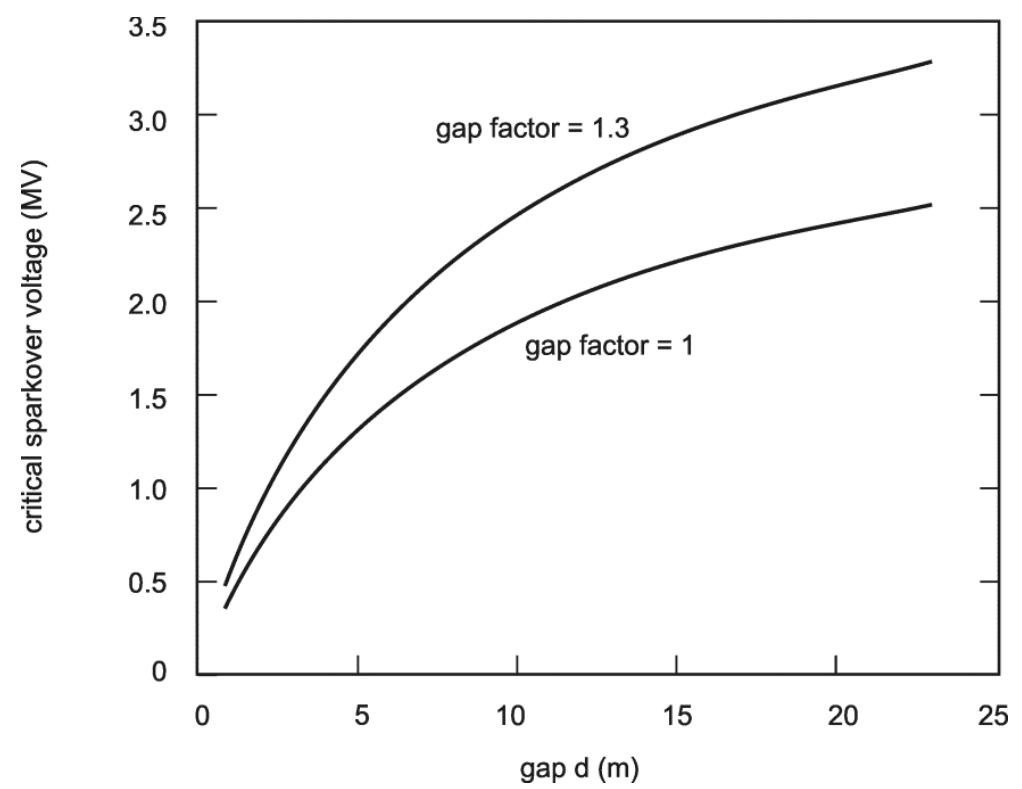

Figure 1 Solution of Gallet equation with two different gap factors

What is not clear from the graph or from the equation is the effect of changing the gap factor on the flashover statistics. The intent of this follow-on report is to examine that effect, and provide some answers regarding the choice of gap factor and its effect on the statistics.

\subsection{Questions to Answer}

What the selection of a gap factor of 1.3 does is this: it makes the gap being considered $30 \%$ stronger than the reference gap for the Gallet equation. That much is clear from the graph in Figure 1. The question it does not answer is how that change affects the probability of a flashover. In order to answer that question, we need to review how the results of the calculation are used.

The Gallet equation deals with the value of a quantity called the critical flashover voltage, or CFO. The $\mathrm{CFO}$ is the voltage of an applied impulse at which a given gap has a 50\% chance of flashing over. The test is done with an impulse generator, and the impulse has a simple shape with a particular rise-time and a longer fall-time. The word "critical" here means that the rise-time has been adjusted 
experimentally to result in the lowest flashover voltage. When the testing is performed, the voltage is gradually increased until the gap flashes over. Many tests are done at each voltage in the series, because there is some statistical spread. When the work is completed for a given gap, it is found that the flashovers tend to cluster around a particular voltage. When the number of flashovers is plotted against voltage, the familiar bell-curve is obtained.

The top of the bell curve gives the voltage at which most flashovers occur. At higher and lower voltages, the chances of there being a flashover are higher or lower. On the low side, the voltage is not sufficient to guarantee a flashover. On the high side there are fewer flashovers because they tend to take place before that value is reached during the test.

A curve can be drawn of the area under the bell curve. This curve is called the cumulative probability distribution, and it relates overall flashover probability for the gap and the voltage. Figure 2 shows a representative example. At the low voltages, there is less than a $50 \%$ chance of flashover. Above the middle of the curve, the likelihood increases until, when the voltage is significantly above the center, the likelihood of a flashover is very great.

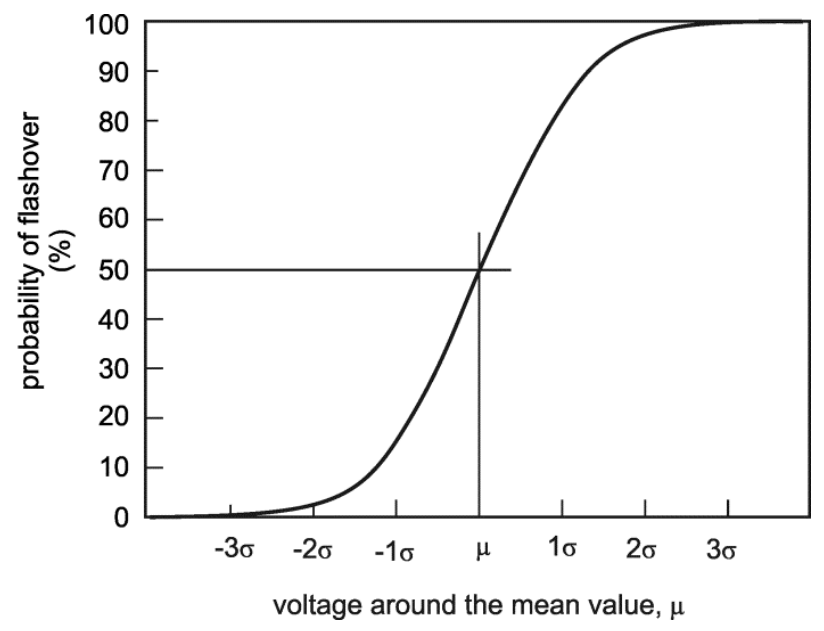

Figure 2 Flashover probability curve

In Figure 2 the voltage scale is shown "normalized." The mean of the distribution of flashovers is shown as $\mu$, and the standard deviation $\sigma$. The curve shown corresponds to that of a "normal" distribution. For a normal distribution, at the mean value, there is a $50 \%$ chance that there will have been a flashover. The curve is symmetrical. At two standard deviations below the mean, there is only a $2.3 \%$ chance of a flashover. At two standard deviations above the mean, there is only a $2.3 \%$ chance that there will not be a flashover.

In tower design, the typical procedure is to design for a very low probability of flashover for a surge whose voltage is estimated. That estimate is typically based on a voltage that can be "designed-in" by means of the surge arrestors installed at the ends of the line. For an EHV line, the surge arrestors may be chosen to be 1.5 per unit, which means that the biggest surge that can be present is limited to 1.5 times the peak value of the line-to-ground voltage. 
If we suppose that the desired flashover probability is set at $0.13 \%$, it is a characteristic of the distribution that the voltage must be limited to 3 standard deviations below the CFO value. It is generally accepted (based on decades of experimental work) ${ }^{2}$ that the standard deviation $(\sigma)$ of the distribution is $5 \%$, and therefore the surge arrestor voltage defines a value that is $85 \%$ of the CFO. That CFO voltage is then used in conjunction with the Gallet equation to find the gap. That will be the gap needed to achieve the $0.13 \%$ probability for a surge given by the surge arrestor value.

The question is then this. What does that $0.13 \%$ flashover probability value become if the voltage is fixed, the gap is fixed, but the gap factor is changed?

We can illustrate the answer with an example. Suppose we start by assuming a gap factor of 1.3, and a line voltage of $765 \mathrm{kV}$ with surge arrestors at 1.4 per unit. The peak value of line-ground voltage of a $765-\mathrm{kV}$ line is $624.5 \mathrm{kV}(765 \times 1.414 / 1.732)$, and the peak value of the surge is therefore this value times 1.4 , or $874 \mathrm{kV}$.

We want that voltage to be $85 \%$ of the CFO, so the CFO must be $874 / 0.85=1028 \mathrm{kV}$. The inverse Gallet equation gives us the gap for this voltage. That is, we can solve

$$
d=\frac{8}{\left(k \cdot \frac{3.4}{U}\right)-1}
$$

with $k=1.3$ and $U=1.028 \mathrm{MV}$, and find a value of $2.42 \mathrm{~m}(7.97 \mathrm{ft})$.

At this point, we have a set of numbers that represent a line with a certain voltage and certain values for the surge arrestors that will limit the overvoltage, and we have a physical gap fixed.

Now we can take the value of the gap, $2.42 \mathrm{~m}$, and use the Gallet equation to find a revised CFO voltage, this time assuming a gap factor of 1.0 instead of 1.3. That is, we solve

$$
U=k \cdot \frac{3.4}{1+\frac{8}{d}}
$$

with $k=1$ and $d=2.42$.

We find that the voltage is $791 \mathrm{kV}$. The surge we are concerned with is still $874 \mathrm{kV}$. (Nothing about the line or the surge arrestors has changed.) Therefore, the surge has a value that is higher than the mean of the assumed distribution. We know right away that there is a probability of flashover of more than $50 \%$.

Is that reasonable? We have fixed the gap at $2.42 \mathrm{~m}$, and we have fixed the surge voltage at $874 \mathrm{kV}$. With a gap factor of 1.3 , that gap has a CFO of $1028 \mathrm{kV}$, and our assumed surge is comfortably below that. With a gap factor of 1.0 , the CFO is reduced to $791 \mathrm{kV}$, and our surge is above the CFO. The gap factor changed by from 1.3 to 1.0. The CFO changed in exactly the same ratio, from 1028 to 791 .

\footnotetext{
${ }^{2}$ Much of the work is exemplified in what is sometimes called the Red Book: the full title is "Transmission Line Reference Book: $345 \mathrm{kV}$ and Above." It was published in 1975 by EPRI, the Electric Power Research Institute. It describes the results of experimental research into line and tower performance of a number of different designs at a number of voltages, in fair weather and foul.
} 
To find the new probability of flashover, we can use the equations for the normal distribution, we can use tabulated data to find the exact probability of flashover, or we can get an approximation from Figure 2. Table I summarizes the probabilities for multiples of sigma for up to $4 \sigma$ either side of the center of the distribution.

Table I. Probabilities for multiples of sigma.

\begin{tabular}{cc|cc}
\hline Sigma multiple & $\begin{array}{c}\text { Probability } \\
\text { in } \%\end{array}$ & Sigma multiple & $\begin{array}{c}\text { Probability } \\
\text { in \% }\end{array}$ \\
\hline-4.0 & 0.0032 & 0.5 & 69.15 \\
-3.5 & 0.02 & 1.0 & 84.13 \\
-3.0 & 0.13 & 1.5 & 93.32 \\
-2.5 & 0.62 & 2.0 & 97.72 \\
-2.0 & 2.27 & 2.5 & 99.38 \\
-1.5 & 6.68 & 3.0 & 99.87 \\
-1.0 & 15.87 & 3.5 & 99.98 \\
-0.5 & 30.85 & 4.0 & 99.99 \\
0.0 & 50.00 & & \\
\hline
\end{tabular}

The table, adapted from a statistics text, ${ }^{3}$ shows the values of what is called the Unit Normal Distribution Function. The probability of flashover occurring at the given sigma value away from the center of the distribution can be read directly. The values at a negative value and the same positive value add to $100 \%$, within rounding error. For a multiplier of 1 , for example, the probability at -1 is $15.87 \%$ and at +1 is $84.13 \%$. The data are the same as the cumulative data plotted in Figure 2 .

The surge voltage is $874 \mathrm{kV}$, which is higher than the CFO by $83 \mathrm{kV}$. The standard deviation of a distribution centered on $791 \mathrm{kV}$ (still assumed to be $5 \%$ ) is $39.6 \mathrm{kV}$, so the applied surge is just over 2 standard deviations above the mean. The table shows there is more than a $97 \%$ chance of flashover. ${ }^{4}$ Changing the assumed gap factor has made what looked like a very small chance of flashover into a virtual certainty.

This result may seem surprising, but it can be explained by reviewing the flashover probability curve of Figure 2. That gentle curve is normalized in terms of the standard deviation. The standard deviation of flashover tests is found experimentally to be about 5\%. That means that the same information could be presented with an abscissa labeled in volts instead of sigmas. The result is shown in Figure 3, where the effect of a change in gap factor can be seen to move the value of the CFO (the 50\% point) and to make the curve steeper in terms of volts. Note that in either case, the standard deviation, at 5\%, gives a relatively steep rise to the probability curves.

\footnotetext{
3 "Introduction to Probability and Statistics for Engineers and Scientists," Sheldon M. Ross, Wiley and Sons, New York, NY, 1987. The data are from Table A3.5.1 on page 482.

${ }^{4}$ It is possible to be more precise, but the reader is cautioned that great precision is not necessarily of great value when looking at these probabilities, since so many of the values in the calculation are based on assumptions. Even the value of the standard deviation, $5 \%$, is an assumption, though it is widely accepted and supported by much experiment.
} 


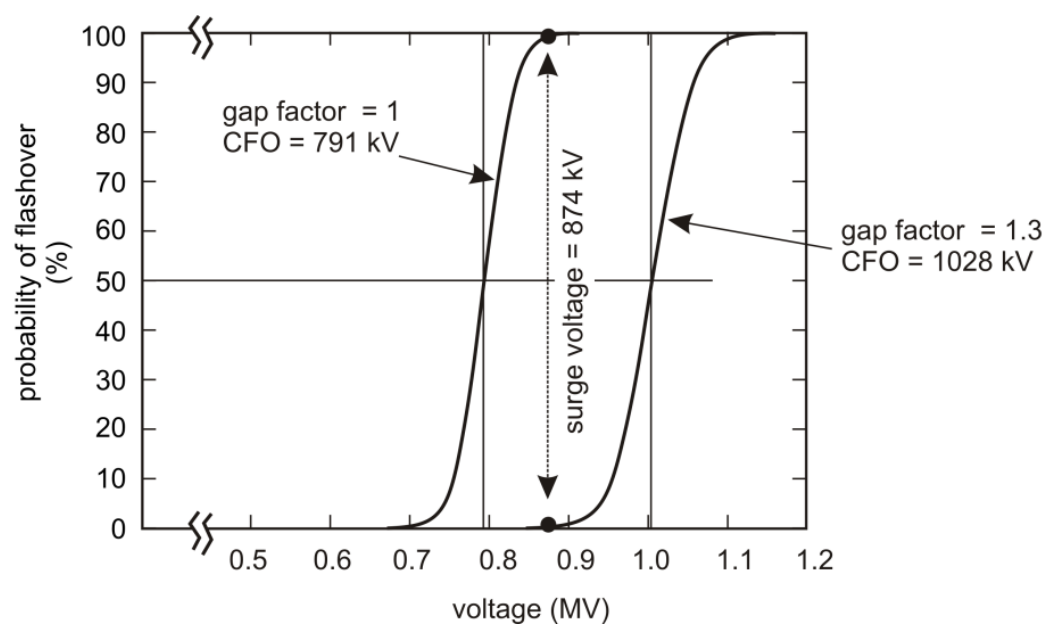

Figure 3 Flashover probability with scale in volts

In the example in Figure 3, a voltage that is comfortably below the mean of the higher curve can certainly be much higher than the mean of the lower curve.

The same result will be found for other assumed line voltages, since our entire discussion scales with voltage. Thus for a $500-\mathrm{kV}$ line, let us assume a gap factor of 1.3, and surge arrestors at 1.5 per unit. The peak value of line-ground voltage of a $500-\mathrm{kV}$ line is $408.2 \mathrm{kV}(500 \times 1.414 / 1.732)$, and the peak value of the surge is therefore this value times 1.5 , or $612 \mathrm{kV}$.

We want that voltage to be $85 \%$ of the CFO, so the CFO must be $612 / 0.85=720 \mathrm{kV}$. The inverse Gallet equation gives us the gap for this voltage. With $k=1.3$ and $U=0.720 \mathrm{MV}$, and find a value of $1.56 \mathrm{~m}$ $(5.11 \mathrm{ft})$.

Now we can take the value of the gap, $1.56 \mathrm{~m}$, and use the Gallet equation to find a revised CFO voltage, this time assuming a gap factor of 1.0 instead of 1.3 . With $k=1$ and $d=1.56$ we find that the voltage is $555 \mathrm{kV}$. The surge, at $612 \mathrm{kV}$ has a value that is higher than the mean of the assumed distribution. We know once again that there is a probability of flashover of more than $50 \%$.

The CFO changed, as before, in the same ratio as the gap factor, from $720 \mathrm{kV}$ to $555 \mathrm{kV}$. Flashover with this surge is practically certain.

\subsection{Summary and Conclusions}

The voltage given by the Gallet equation is scaled by the gap factor. If a given gap is modeled by too large a gap factor, the gap will be estimated as too strong. If the same gap is modeled by a lower gap factor, it will appear to be capable of withstanding only a lower voltage.

The probability of flashover is generally regarded as having a normal distribution with a standard deviation of 5\%. The center of the distribution is the value called critical flashover voltage. An impulse 
with a voltage only $15 \%$ above that value will have approximately $99.9 \%$ chance of flashover. On the other hand, with a voltage that is only $15 \%$ lower than the CFO value, only about $0.1 \%$ of impulses will flash over.

The flashover statistics for a given gap change significantly if the gap factor assumption is changed from 1.3 to 1.0. These two numbers differ by $30 \%$. The change in flashover statistics resulting from the change in gap factor, and hence the calculated CFO, means that there is almost no overlap for the flashover curves for the two gap factors.

What that means, for these two numbers, is that a gap and a voltage that would have a very small chance of flashover with a gap factor of 1.3 is virtually certain to flash over if the factor should have been 1.0 . 